\title{
MINIMIZAÇÃO DE CUSTOS DE TRANSPORTE FLORESTAL COM A UTILIZAÇÃO DA PROGRAMAÇÃO LINEAR
}

\author{
Ricardo Berger ${ }^{1}$ \\ RomanoTimofeiczyk $\mathrm{Jr}^{2}$ \\ Celso Carnieri ${ }^{3}$ \\ Pedro Giovani Lacowicz ${ }^{4}$ \\ José Sawinski Junior ${ }^{5}$ \\ Alexandre Anders Brasil ${ }^{6}$
}

\begin{abstract}
RESUMO
A complexidade do planejamento do transporte florestal de madeira levou ao desenvolvimento de um método que auxiliasse na determinação das melhores rotas a serem seguidas por caminhões, para se conseguir um menor custo possível para um máximo volume de madeira posto pátio. Baseando-se na solução do problema do transporte através da programação linear, o método descrito neste trabalho permite, em uma situação de diversas origens e um único destino, análises quanto ao número ideal de viagens, carga ótima por veículo, menor custo por unidade de volume e quilometragem máxima mensal. Os resultados obtidos nos estudos de casos mostram adequação econômica do método de planejamento do transporte por programação linear, havendo um aumento de $22,70 \%$ no volume de madeira posto pátio e uma redução de $18,33 \%$ no custo por estéreo posto pátio.

Palavras chave: Pesquisa Operacional, transporte de madeira, custos de transporte
\end{abstract}

\section{FORESTRY TRANSPORTATION COSTS MINIMIZATION USING LINEAR PROGRAMMING}

\begin{abstract}
The complexity of planning the forest transport leads to developing of a method to aid in the determination of the best routes to be used for trucks, aiming to the lower cost possible for de maximum volume of wood transported. Aiming to the solution of this problem of transport trough linear programming, the method reported in this work allows in situation of several wood origins and just one destine, analyzes on the ideal number of traveling, the optimum truck loading, the lower cost per wood unit volume and the maximum monthly truck mileage. The results obtained in this case study showed economic adequation of the method to transport planning using linear programming, accounting the increase of $22,7 \%$ in the wood volume delivery and reduction of $18,33 \%$ in the cost on the same number of trucks.
\end{abstract}

Key-words : operation research, wood transportation, transportation costs

\section{INTRODUÇÃO}

Tendo em vista que o transporte de madeira é uma das atividades que mais geram custos dentro de uma empresa florestal, e observando-se ainda a complexidade do mesmo devido ao grande número de variáveis envolvidas no processo, tais como variáveis climáticas, distâncias entre a floresta e a unidade de processamento da madeira, custos de manutenção, combustível, lubrificantes, pneus, tarifas e outros, torna-se necessária uma tomada de decisão visando minimizar os custos e as distâncias percorridas.

Nesse contexto, o presente trabalho vem mostrar como se desenvolve o transporte florestal em uma empresa situada na cidade de

\footnotetext{
${ }^{1}$ Professor Dr. do Depto de Economia Rural e Extensão da UFPR. Email: berger@floresta.ufpr.br

${ }^{2}$ Professor M.Sc. do Depto de Economia Rural e Extensão da UFPR; Email: romano@,floresta.ufpr.br

${ }^{3}$ Professor Dr. Departamento de Matemática da UFPR

${ }^{4}$ Doutorando em Engenharia Florestal da UFPR. Email: giovani@floresta.ufpr.br

${ }^{5}$ Engenheiro Florestal, M.Sc.

${ }^{6}$ Mestrando em Engenharia Florestal da UFPR. Email: brasil@floresta.ufpr.br
} 
Canoinhas (SC), apontando alternativas para que se consiga a otimização do processo, tanto do ponto de vista da maximização de carga transportada quanto da minimização de custos. Para tanto, utiliza-se uma das mais promissoras ferramentas para equacionar e solucionar o complexo universo de informações que se apresentam no setor de transporte florestal de madeira, que é a programação linear. Dentro desse conjunto, quantificou-se os custos das atividades de transporte florestal visando a buscar alternativas para minimização desses custos e maximização do volume de madeira posto pátio, utilizando esta ferramenta matemática. Portanto, o presente trabalho tem como objetivo minimizar os custos de transporte de madeira de uma empresa florestal, que possui várias origens e um único destino para o suprimento de matéria prima da empresa em estudo.

\section{REVISÃO DE LITERATURA}

O transporte é uma das atividades que mais geram custos dentro do setor florestal, tanto no Brasil quanto no exterior. A escolha do meio de transporte deve considerar o sistema de mecanização que está sendo empregado na floresta, além de uma série de outras variáveis. O fato é que, com a evolução tecnológica dos veículos pesados, existem novas opções que vão desde composições mais simples, como romeu e julieta (caminhão com um reboque) até o treminhão (caminhão com dois reboques) ou rodotrem (cavalo-mecânico mais dois semi-reboques ou um semi-reboque e um reboque) (SAAB SCANIA, 1985).

A importância que o caminhão adquiriu como meio de transporte é um dos fenômenos de maior significado em nossos dias. Essa importância é decorrente não só do elevado volume de carga movimentada entre as empresas produtoras, intermediárias $\mathrm{e}$ consumidoras, mas também pelo fato de ser fatalmente necessário na interligação entre pontos de origem ou destino das mercadorias (Machado, 1985).

Existem diversos fatores que afetam o desempenho de caminhões e o custo do transporte rodoviário florestal. Entre estes fatores podem-se citar aqueles relacionados com o tipo de veículo, com a rede rodoviária florestal, com as condições locais (clima e altitude), com o método de trabalho e, ainda, com os fatores inerentes ao ser humano (Leite, 1992).

Para o setor nacional, o custo de madeiras de florestas implantadas varia entre 38 e $66 \%$ do custo final de aquisição da madeira posto fábrica, para as distâncias médias entre 45 e $240 \mathrm{~km}$ (Salmeron, 1984). Malinovski e Fenner (1986) expõem que o custo de transporte circunda na faixa de $40 \%$ dos custos da empresa. Outra forma comparativa foi colocada por Balloni (1997), onde destaca que no custo de produção do papel imprensa do Paraná, 3,7\% corresponde à madeira em pé e $7,2 \%$ a atividades de colheita e transporte.

Segundo (Leite, 1992), a distância é um dos fatores que mais afetam o custo de transporte e este varia de acordo com a localização da fábrica em relação às áreas de produção da madeira. Seja pelo sistema de transporte rodoviário, ferroviário ou hidroviário, o custo do transporte da madeira varia diretamente com a distância. Silversides (1978) expõe que a distância é um dos principais fatores que governa os custos do transporte, pois determina o volume de madeira a ser transportado por turno ou dia de trabalho, em cada tipo de composição veicular, e quanto mais extenso for o trajeto, maior será o custo unitário por volume de madeira transportada. Para distâncias longas, a principal forma de diminuição dos custos de transporte é a utilização de composições veiculares de grande capacidade de carga.

Marques (1994) cita também o tempo de carga e de descarga como outro fator que influência o custo de transporte. Isard (1975), descreve que o custo de transporte pode ser altamente afetado pelo tempo de carga e descarga. Os tempos de carga e descarga são definidos em uma das suas obras como "custo terminal", tornando-se altamente expressivos quando o transporte é efetuado em pequenas distâncias e menos expressivos em grandes distâncias (em curtas distâncias, os veículos tendem a realizar mais cargas e descargas do que em longas distâncias, numa mesma unidade de tempo).

Segundo Malinovski e Fenner (1986), o tempo de espera deve ser o mínimo possível e, para tanto, deve-se optar por um sistema de 
carga e descarga que seja o mais rápido e seguro possível e de baixo custo, pois a fila de transporte não está só relacionada com o número de caminhões, mas também com o rendimento ou produtividade dos carregadores.

$\mathrm{O}$ estudo visando à organização e à racionalização das operações do transporte florestal rodoviário poderá representar uma grande economia de recursos para as empresas do setor, bem como aumentar a eficiência operacional e, conseqüentemente, a produtividade dos caminhões (Leite, 1992).

$\mathrm{O}$ transporte rodoviário florestal representa parcela significativa no custo final da madeira posta pátio da fábrica e que, para a minimização desse custo, maneiras eficientes, como pesquisas científicas, devem ser utilizadas, para a obtenção de níveis elevados de eficiência econômica nos setores de exploração e transporte florestal (Brant, 1984).

Seixas (1992), ressalta a necessidade do planejamento do transporte, procurando sempre considerar a escolha dos veículos mais indicados para uma determinada característica de rede viária, o número de turnos mais econômicos, adequação do fluxo de veículos, respeitando a infra-estrutura de carga e descarga, mesmo considerando-se que a frota seja de terceiros. Cabe à empresa realizar tal planejamento, pois através do mesmo possibilitar-se-á um aumento da eficiência no uso dos veículos, maiores ganhos por parte dos proprietários do veículo e redução do valor pago pelo frete em virtude da racionalização do processo.

Arce (1998), descreve que o planejamento florestal principal requer decisões racionais, levando em consideração a disponibilidade de veículos, os produtos a serem transportados, as rotas a serem utilizadas, os horários de trabalho dos caminhões, pontos de produção ou clientes, dentre outras variáveis que podem afetar o planejamento.

A programação linear é uma poderosa ferramenta de planejamento e vem sendo largamente utilizada em todo o mundo. No setor florestal, seu uso tem-se difundido bastante, principalmente nos países desenvolvidos (Martini e Leite, 1988).

\section{MATERIAIS E MÉTODOS}

O trabalho dividiu-se basicamente em duas etapas. A primeira consistiu no levantamento dos custos de transporte florestal da empresa e a segunda foi à utilização de modelos matemáticos para minimização destes custos, através do método Simplex de Programação Linear.

A empresa possui uma frota própria de cinco caminhões, todos trucados, sendo que dois caminhões não possuem assoalho, podendo ser utilizado somente no transporte de toras longas, constituindo assim um fator limitante para o transporte de tora curta. O carregamento de madeira nos caminhões com assoalho pode ser efetuado no sentido transversal ou longitudinal, tora curta e tora longa respectivamente, dando maior versatilidade a estes veículos. A empresa necessita de três diferentes tipos de toras:

a) Tora curta para serraria;

b) Tora longa para serraria;

c) Tora longa para torno.

O produto tora curta para serraria é obtido em uma Fazenda localizada a 35 quilômetros da indústria, sendo 30 quilômetros de asfalto e 5 de estrada de terra. Em condições ideais de tráfego, com sol e estrada firme, é possível realizar de 3 a 4 viagens por dia e por caminhão neste local.

O produto tora longa para serraria é obtido em uma Fazenda situada a 51 quilômetros da indústria, sendo 23 quilômetros de asfalto e 28 de estrada de terra. Em condições ideais de tráfego, um caminhão pode realizar até três viagens por dia deste local, visto que o carregamento se dá no sentido longitudinal, dinamizando o processo. Nessa fazenda, apenas dois caminhões sem assoalho fazem o transporte, e quando necessário um caminhão com assoalho dá apoio a essa equipe.

O produto tora longa para torno é obtido em uma Fazenda localizada a 30 quilômetros da indústria, sendo 27 quilômetros de asfalto e 3 de estrada de terra. É o local mais próximo e de mais fácil acesso, sendo que os caminhões poderiam fazer até 5 viagens por dia se o sistema de carregamento assim permitisse. Em média saem 3000 estéreos de madeira por mês desse local. 
De acordo com as informações do setor de planejamento da empresa em estudo, o objetivo da empresa é transportar 8000 estéreos de madeira por mês, sendo 3000 estéreos de tora longa para torno, e 5000 estéreos para serraria. Destes, 3000 estéreos seriam de tora curta e 2000 de tora longa. A maior dificuldade da empresa está sendo com o suprimento de tora curta para serraria.

\section{Coleta dos dados}

Realizou-se um estudo detalhado sobre cada caminhão coletando-se informações durante oito meses (Janeiro a Agosto de 1997). Nesse estudo, foram levantadas informações referentes a carga ótima por veículo, tempo de deslocamento da fazenda até a indústria, dias trabalhados, volume total de madeira transportado, média diária de madeira transportada até o pátio da indústria, média de viagens por dia, quilometragem média diária, combustível consumido por dia e consumo médio $(\mathrm{km} / \mathrm{litro})$.

\section{Custos}

O custo total se refere a todos os custos envolvidos no processo, e para uma melhor compreensão, foi dividido em custos fixos e variáveis.

Como custos fixos, consideram-se os custos que não variam com a produção, isto é, mantém-se constantes, independente do uso do equipamento. Os custos fixos são: depreciação, salário de motoristas, licenciamento e seguro obrigatório, custos administrativos, taxa de juro.

Como custos variáveis, foram considerados todos os custos que variam com a produção, ou seja: combustíveis, lubrificantes, pneus e manutenção.

\section{Custos fixos}

a) Depreciação seguinte fórmula:

A depreciação foi determinada pela

$$
\mathrm{D}=(\mathrm{VA}-\mathrm{VR}) / \mathrm{n}
$$

Onde:

$\mathrm{D}=$ Depreciação (em R $\$ /$ mês);

$\mathrm{VA}=$ Valor de aquisição;

$\mathrm{VR}=$ Valor residual; $\mathrm{n}=$ Vida útil (em meses).

b) Custos de Licenciamento e Seguro Obrigatório

Coletaram-se os dados junto a um despachante local, onde a empresa efetua o emplacamento e licenciamento de seus veículos. Para o cálculo deste custo utilizou-se a seguinte expressão:

$$
\mathrm{LS}=(\mathrm{CL}+\mathrm{CS}) / 12
$$

Onde:

LS $=$ Custos de licenciamento e seguro obrigatório (R $\$ /$ mês);

$\mathrm{CL}=$ Custo de licenciamento;

$\mathrm{CS}=$ Custo de seguro obrigatório.

c) Salários dos motoristas

Foram obtidos junto ao Setor de Pessoal da empresa, sendo que estes salários são compostos por três itens, conforme demonstrado na fórmula a seguir:

$$
\mathrm{SM}=\mathrm{S}+\mathrm{E}+\mathrm{C}
$$

Onde:

$$
\begin{aligned}
& \mathrm{S}=\text { salário (em } \mathrm{R} \$ / \mathrm{mês}) ; \\
& \mathrm{E}=\text { encargos; } \\
& \mathrm{C}=\text { comissões. }
\end{aligned}
$$

d) Custo Administrativo

O Setor de Transporte Florestal da empresa está subordinado a uma gerência. Portanto, este custo foi quantificado com auxílio do setor de contabilidade, que forneceu dados referentes ao custo total dispensado com a gerência e encargos. Fez-se uma média mensal dos oito meses (janeiro-agosto), obtendo um custo administrativo mensal referente ao transporte florestal. $\mathrm{O}$ valor obtido foi dividido pelo número de caminhões (5), obtendo-se assim o custo administrativo médio mensal por caminhão.

e) Custo de oportunidade pelo uso do capital (juro)

Foi considerado para o presente trabalho uma taxa de $12 \%$ a.a.

\section{$\underline{\text { Custos variáveis }}$}

a) Combustível

Foram coletadas informações de consumo de cada caminhão durante oito meses junto ao Departamento de Manutenção Mecânica da Empresa. Através da fórmula 
abaixo, foi calculado o custo mensal de combustível.

$$
\mathrm{Co}=\mathrm{Pcl} . \mathrm{U} . \mathrm{fa}
$$

Onde:

Co $=$ Custo com combustível (em $\mathrm{R} \$ / \mathrm{mês})$;

$\mathrm{Pcl}=$ Preço por litro de combustível;

$\mathrm{U}=$ Total de quilometragem mensal de todos os caminhões;

$\mathrm{fa}=$ Quilometragem média de todos os caminhões por litro.

b) Lubrificantes

As informações necessárias para o cálculo de custos de lubrificantes também foram obtidas junto ao Departamento de Manutenção Mecânica da empresa, relativo ao consumo de cada caminhão durante os oito meses. O custo de lubrificantes foi calculado da seguinte forma:

$$
\mathrm{LU}=\mathrm{Co} . \mathrm{Fc}
$$

Onde:

$\mathrm{LU}=$ Custo de lubrificantes (R\$/mês);

$\mathrm{Co}=$ Custo com combustível;

$\mathrm{Fc}=$ Fator de correção $(20 \%)$.

c) Custos de Pneus e Acessórios

Realizou-se uma pesquisa de mercado com a finalidade de obter o menor custo de pneus e recapes. Para a determinação do intervalo médio de tempo entre cada troca de pneus ou recapes, foram utilizadas informações do Departamento de Manutenção Mecânica e do Setor de Compras da empresa.

Considerou-se ainda um "fator de segurança" no final da expressão, como um coeficiente de segurança para pneus estourados e sem condições de recuperação. $O$ valor mínimo para este fator é 1,1 , que eqüivale a $10 \%$. A fórmula a seguir fornece os custos com pneus e acessórios.

$$
\mathrm{Pn}=(\mathrm{Ppn}+\mathrm{Pcn}+\mathrm{Pr}) . \mathrm{Np} . \mathrm{fs} / \mathrm{np}
$$

Onde:

$\mathrm{Pn}=$ Custo de pneus e acessórios;

Ppn $=$ Preço dos pneus e acessórios;

$\mathrm{Pcn}=$ Preço de conserto;

$\operatorname{Pr}=$ Preço de recapagem;

$\mathrm{Fs} / \mathrm{np}=$ Fator de segurança por pneu.

d) Manutenção Mecânica
Os custos de manutenção dos veículos foram obtidos com auxílio do setor de contabilidade da empresa, e são divididos em custo de peças e custo de oficina (salários e encargos dos mecânicos).

e) Lavagem (LA)

Estipulou-se ainda um custo referente a lavagens dos veículos (LA), baseado em pesquisas de mercado. Cada caminhão é submetido a duas lavagens mensais, onde após a lavagem é efetuada a lubrificação do veículo, troca de óleo se necessário for, e reparos mecânicos de pequeno porte.

\section{Determinação do custo total}

Para determinação do custo total por caminhão, somaram-se os custos fixos e variáveis. A fórmula global que forneceu o custo total $(\mathrm{CT})$ do transporte em $\mathrm{R} \$ /$ mês por caminhão foi:

$$
\begin{gathered}
\mathrm{CT}=\mathrm{D}+\mathrm{Co}+\mathrm{Lu}+\mathrm{Ma}+\mathrm{Pn}+\mathrm{LS}+\mathrm{SM}+ \\
\mathrm{CA}+\mathrm{LA}+\mathrm{i} \%
\end{gathered}
$$

Onde:

$\mathrm{CT}=$ Custo total;

$\mathrm{D}=$ Depreciação;

Co $=$ Custos de combustíveis;

$\mathrm{Lu}=$ Custos de lubrificantes;

$\mathrm{Ma}=$ Custo de manutenção (Peças e

Salários de mecânicos);

$\mathrm{Pn}=$ Custos de pneus e recapes;

$\mathrm{LS}=$ Licenciamento e seguro obrigatório;

$\mathrm{SM}=$ Salário dos motoristas;

$\mathrm{CA}=$ Custos administrativos;

LA = Lavagens;

$\mathrm{i} \%=$ custo de oportunidade.

A fim de obter o custo por estéreo de madeira transportada, dividiu-se o custo total pelo volume total transportado. No caso de distâncias de transporte variáveis, há distorção no custo por tonelada transportada, já que uma quantidade de carga quando transportada em distâncias diferentes tem custo diferente (quanto maior a distância, maior o custo). Para corrigir tal distorção, o parâmetro $\mathrm{R} \$$ /estéreo passa a ser avaliado em $\mathrm{R} \$ /$ estéreo $/ \mathrm{km}$.

O Modelo de Programação Linear 
Muitos problemas de administração e economia tratam da alocação de recursos limitados - dinheiro, pessoal, materiais, máquinas, espaço, tempo - tendo em vista maximizar algum índice de performance ou minimizar alguma medida de custo. As técnicas matemáticas para planejar tais alocações constituem a programação matemática. $\mathrm{O}$ caso particular no qual o índice de performance ou o de custo é uma função linear e as restrições sobre a disponibilidade ou utilização de recursos são expressáveis como equações ou desigualdades lineares, é denominado de "programação linear".

Mais especificamente, o problema da programação linear envolve a maximização ou minimização de uma função linear de variáveis primárias denominada função objetivo, sujeita a um conjunto de igualdades ou desigualdades lineares, denominadas restrições.
Matematicamente, o problema de programação linear para a maximização é escrito da seguinte forma:

Maximizar uma função objetivo:

$$
\operatorname{Max} \mathrm{Z}=\mathrm{c}_{1} \mathrm{X}_{1}+\mathrm{c}_{2} \mathrm{X}_{2}+, \ldots \ldots,+\mathrm{cnXn} \text {, }
$$

sujeita às seguintes restrições:

$$
\begin{gathered}
a_{11} X_{1}+a_{12} X_{2}+\ldots .+a_{1 n} X_{n} \leq b_{1} \\
a_{21} X_{1}+a_{22} X_{2}+\ldots .+a_{2 n} X_{n} \leq b_{2} \\
\ldots . \\
\ldots . . \\
a_{m 1} X_{1}+a_{m 2} X_{2}+\ldots .+a_{m n} X_{n} \leq b_{n} \\
X j \geq 0 j=1,2,3, . ., n
\end{gathered}
$$

Em todo problema de otimização apenas uma função pode ser otimizada. Os demais objetivos devem ser expressos como restrições. Então, o principal objetivo, que foi minimizar o custo, constituiu a função objetivo. Os demais objetivos são as restrições, sendo estes, o volume mínimo mensal a ser transportado, e a quilometragem máxima percorrida pelos caminhões.

\section{RESULTADOS}

A tabela 1, que segue abaixo, mostra em detalhes o custo fixo, variável e a composição do custo total dos cinco veículos em estudos.

Tabela 1: Custo total dos veículos (R $\$ /$ mês)

Table 1: Vehicles total cost (R\$/month)

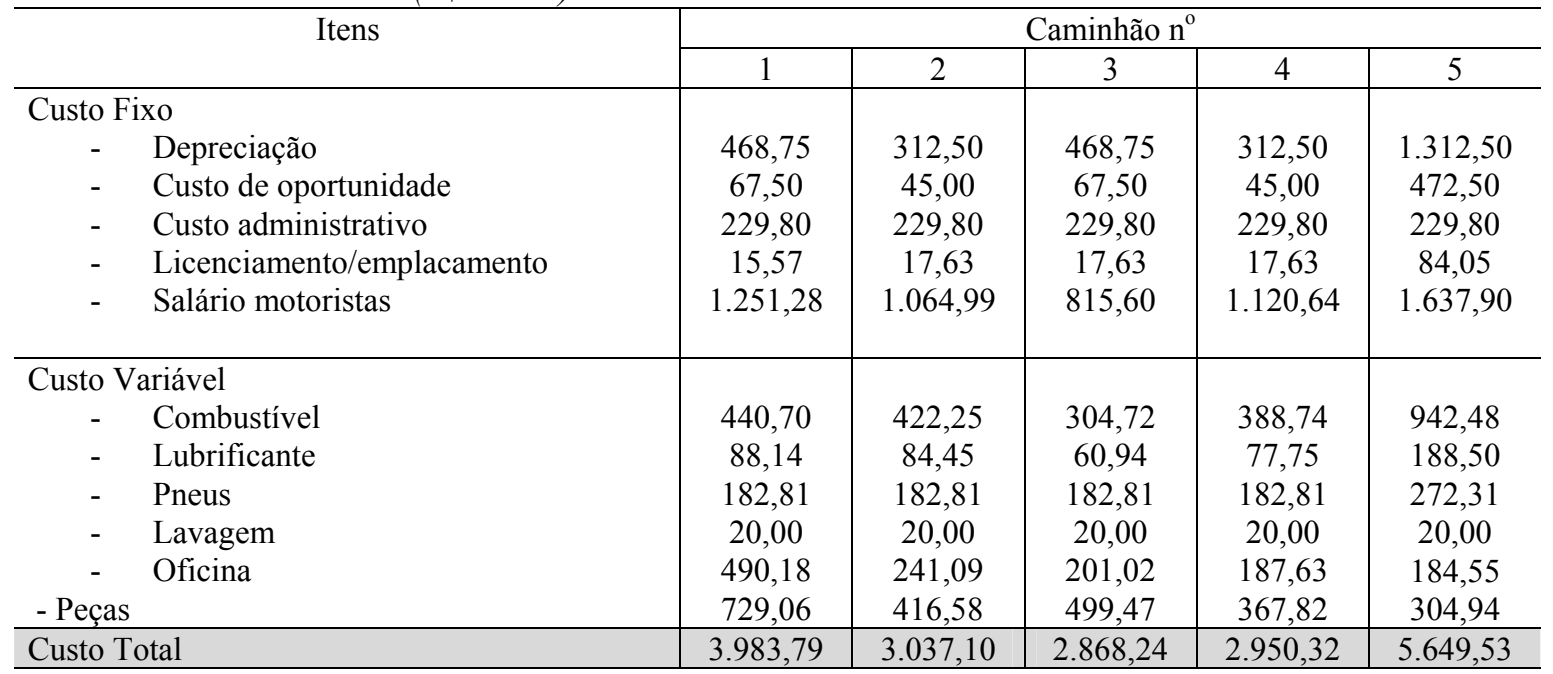


Somando-se os custos totais mensais de cada caminhão, chega-se ao valor de R\$ 18.488,98. Pode-se verificar que o veículo 5 apresenta valores maiores principalmente quanto ao custo de Depreciação, em relação aos outros veículos, devido ao fato do valor de aquisição deste ser mais elevado, o que fornece um valor depreciativo médio mensal mais elevado. $O$ custo de peças e oficina para o veículo 5 é o menor dentre todos os veículos, devido ao fato de ser um veículo novo, apresentando assim poucos custos com reposição de peças e manutenção mecânica, fornecendo uma maior eficiência com maior número de horas trabalhadas. Como o veículo 5 permanece pouco tempo no setor de manutenção mecânica, ele consegue efetuar um número maior de viagens, o que eleva o custo de salário do motorista devido ao fator comissões, que é pago pelo número de viagens. Este veículo, tem o consumo de combustível e lubrificantes mais elevado que os demais veículos devido ao maior número de viagens e maior potência do motor e capacidade de carga.

Deve-se ressaltar que o custo mais elevado nesse caso, não quer dizer que o custo por estéreo posto pátio por este caminhão seja mais elevado, sendo que o custo mais elevado do veículo 5 pode ser compensado pelo alto volume de madeira transportado por intervalo de tempo quando compara-se este veículo com os demais.

Através dos dados referentes ao custo total mensal por caminhão, obtêm-se o custo por quilômetro rodado, dividindo-se o custo total pela quilometragem média mensal de cada caminhão. Para se obter o custo por estéreo por quilômetro, divide-se o custo por quilômetro rodado pela capacidade de carga do veículo. O custo por estéreo posto pátio é obtido dividindo-se o custo total pelo volume médio de madeira transportada por mês (tab. 2).

Tabela 2: Custos por quilômetro rodado, estéreo por quilômetro e estéreo posto pátio

Table 2: Costs by run kilometer, board by kilometer, and yard disposed board

\begin{tabular}{l|c|c|c|c|c}
\hline Custo por Caminhão $\mathrm{n}$. & 1 & 2 & 3 & 4 & 5 \\
\hline Custo/km rodado (R\$) & 1,21 & 0,67 & 1,08 & 0,60 & 0,98 \\
Custo/estéreo/km (R\$) & 0,069 & 0,031 & 0,047 & 0,028 & 0,036 \\
Custo/estéreo posto pátio (R\$) & 5,52 & 2,95 & 4,47 & 2,66 & 3,24 \\
\hline
\end{tabular}

Os elevados custos dos veículos 1 e 3 , podem ser explicados pela baixa quilometragem média mensal. Esta baixa quilometragem média mensal deve-se ao fato desses veículos terem permanecido na oficina por um a dois meses para reforma. Se este período em que o veículo permaneceu parado para reforma fosse excluído do cálculo, os valores seriam bem próximos aos dos outros veículos, porém este procedimento não representaria a realidade operacional.

$\mathrm{O}$ veículo 1 tem os custos mais elevados devido a sua baixa capacidade de carga. Apesar de ser um veículo eficiente quanto a quilometragem mensal, sua capacidade reduzida de carga faz com que o seu custo por estéreo posto pátio seja o mais elevado.

\section{Minimização de Custos Através da Programação Linear}

Após a mensuração e valoração dos fatores de produção efetuou-se a minimização dos custos de transporte de madeira na respectiva empresa florestal em estudo. A função objetivo foi submetida à restrições de quilometragem máxima mensal e volume mínimo a ser transportado.

Função objetivo:

$\operatorname{Min} Z \rightarrow 72,6 x_{11}+123,42 x_{12}+84,7 x_{13}+$
$40,2 x_{21}+68,34 x_{22}+64,8_{31}+110,16 x_{32}+$
$75,6 x_{33}+36,0 x_{41}+61,20 x_{x 42}+58,8_{x 51}+$
$99,966_{x 52}+68,6_{x} 53$

Os valores numéricos são conseguidos multiplicando-se o custo por quilômetro rodado pela distância total de uma viagem (ida e volta). Assim, o primeiro valor da equação $(72,6)$ foi conseguido multiplicando o custo por quilômetro rodado para o caminhão 1 
( $\mathrm{R} \$ 1,21)$ pela distância total até a fazenda 1 (São João $=60$ quilômetros). Então, 1,21 x 60 $=\mathrm{R} \$ 72,6$ para este caminhão fazer uma viagem completa até a fazenda 1 . Adota-se este procedimento para todos os caminhões, sendo o valor numérico correspondente ao custo em reais para que o veículo realize uma viagem completa para cada fazenda.

As variáveis $(\mathrm{x} 11, \mathrm{x} 12, \ldots \mathrm{x} 53)$, correspondem ao número de viagens que o veículo deverá fazer para cada fazenda, como consta tabela 3 .

Tabela 3: Variáveis do modelo

Table 3: Modelling variables

\begin{tabular}{c|c|c|c}
\hline Veículo & $\begin{array}{c}\text { Fazenda 1 (São João }=60 \mathrm{~km} \\
\text { total) }\end{array}$ & $\begin{array}{c}\text { Fazenda 2 (Lageado }=102 \mathrm{~km} \\
\text { total) }\end{array}$ & $\begin{array}{c}\text { Fazenda 3 (Rio Dareia }=70 \mathrm{~km} \\
\text { total) }\end{array}$ \\
\hline 1 & $\mathrm{x}_{11}$ & $\mathrm{x}_{12}$ & $\mathrm{x}_{13}$ \\
2 & $\mathrm{x}_{21}$ & $\mathrm{x}_{22}$ & $\mathrm{x}_{33}$ \\
3 & $\mathrm{x}_{31}$ & $\mathrm{x}_{32}$ & \\
4 & $\mathrm{x}_{41}$ & $\mathrm{x}_{42}$ & $\mathrm{x}_{53}$ \\
5 & $\mathrm{x}_{51}$ & $\mathrm{x}_{52}$ & \\
\hline
\end{tabular}

Não existem as variáveis x23 e x43, devido ao fato que os veículos 2 e 4 não possuem assoalho em sua carroceria, e portanto não podem transportar tora curta, que é o produto extraído da fazenda 3.

A função objetivo foi então submetida a restrições de quilometragem máxima e carga mínima.

Quilometragem máxima:

$$
\begin{aligned}
& 60 \mathrm{x}_{11}+102 \mathrm{x}_{12}+70 \mathrm{x}_{13} \leq 3.500(\mathrm{~km}) \\
& 60 \mathrm{x}_{21}+102 \mathrm{x}_{22} \leq 4.300(\mathrm{~km}) \\
& 60 \mathrm{x}_{31}+102 \mathrm{x}_{32}+70 \mathrm{x}_{33} \leq 3.500(\mathrm{~km}) \\
& 60 \mathrm{x}_{41}+102 \mathrm{x}_{42} \leq 4.300(\mathrm{~km}) \\
& 60 \mathrm{x}_{51}+102 \mathrm{x}_{52}+70 \mathrm{x}_{53} \leq 6.200(\mathrm{~km})
\end{aligned}
$$

Onde os coeficientes $(60,102$ e 70$)$ correspondem a quilometragem total de uma viagem para uma dada fazenda, e as variáveis (x11, x12, etc.) correspondem ao número de viagens necessárias.

\section{Carga mínima:}

$$
\begin{aligned}
& 17,29 \times 11+21,70 \times 21+23,05 \times 31+21,7 \times 41+ \\
& 27,34 \mathrm{x}_{51} \geq 2.000 \text { (estéreos) }
\end{aligned}
$$

$17,29 \times 12+21,70 \times 22+23,05 \times 32+21,7 \times 42+$ $27,34 \mathrm{x}_{52} \geq 1.800$ (estéreos)

$$
\begin{aligned}
& 17,29 \mathrm{x}_{13}+23,05 \mathrm{x}_{33}+27,34 \mathrm{x}_{53} \geq 2.750 \\
& \text { (estéreos) }
\end{aligned}
$$

Onde os coeficientes $(17,29 ; 21,70$; etc.) correspondem a carga ótima por viagem e as variáveis $\left(\mathrm{x}_{11}, \mathrm{x}_{12}\right.$, etc.) correspondem ao número de viagens.

Para os valores iniciais $(3000+2000+$ $3000=8000$ estéreos por mês), não existe solução possível. Iniciou-se então a flexibilização destes valores, para verificar-se onde está localizado o ponto máximo de volume de carga transportado.

Os valores acima, foram reduzidos então para:

* 2000 estéreos de toras para torno;

* 1800 estéreos de tora longa para serraria;

* 2750 estéreos de tora curta para serraria.

Chegou-se então aos seguintes resultados (tab. 4)

Tabela 4: Número ideal de viagens para os caminhões por fazenda, e volumes transportados

Table 4: Ideal number of trucks journey by farm, and transported volume

\begin{tabular}{c|c|c|c|c|c}
\hline Veículo & $\begin{array}{c}\text { Fazenda 1 (São } \\
\text { João) }\end{array}$ & Fazenda 2 (Lageado) & $\begin{array}{c}\text { Fazenda 3 (Rio } \\
\text { Dareia) }\end{array}$ & $\begin{array}{c}\text { Total } \\
\text { (viagens) }\end{array}$ & $\begin{array}{c}\text { Total } \\
\text { (estéreos) }\end{array}$ \\
\hline 117 & 0 & 0 & 49 & 49 & 847,21 \\
123 & 0 & 43 & 0 & 43 & 933,1 \\
124 & 20 & 0 & 34 & 54 & $1.244,7$ \\
128 & 72 & 0 & 0 & 72 & $1.562,4$ \\
143 & 0 & 33 & 42 & 75 & $2.050,5$ \\
\hline Total & 92 & $1.835,32$ & $2.779,19$ & $6.637,91$ & $6.637,91$ \\
\hline total estéreos & $2.023,40$ & & \\
\hline
\end{tabular}

O custo total da atividade, conseguido através da função objetivo foi R\$ 19.534,65, 
Com o custo real médio mensal de $\mathrm{R} \$$ 18.488,98 consegue-se transportar um volume médio de 5.130 estéreos por mês. Com o valor teórico conseguido pela função objetivo, conseguiria-se aumentar este valor para 6.637,91 estéreos por mês. Assim, o planejamento de rotas determinado por programação linear, conseguiria um aumento de 1.507 estéreos por mês, com um pequeno aumento no custo. Porém, para cumprir as rotas determinadas pela programação linear, depende-se de três carregadores florestais (um em cada fazenda), o que não acontece atualmente, sendo que a empresa possui apenas dois carregadores florestais.

Em termos gerais, o custo de transporte da empresa em estudo atinge na atualidade as cifras de $\mathrm{R} \$ 3,60$ por estereo ( $\mathrm{R} \$$ 18.488,98 / 5.130 estereos) e com o auxílio da programação linear este custo poderia ser reduzido para $\mathrm{R} \$ 2,94 \quad \mathrm{R} \$ 19.534,65$ / $6.637,91$ estereos), o que corresponde a uma redução percentual de $18,33 \%$.

\section{CONCLUSÕES}

- O método utilizado neste trabalho pode ser empregado como ferramenta de auxílio na determinação das opções mais adequadas quanto às rotas a serem seguidas pelos veículos do transporte rodoviário florestal, visando minimização de custos e maximização do volume de madeira transportada, na situação aqui enfocada de diversas fontes e um único destino.

- O modelo teórico conseguido mediante a utilização da programação linear, esbarra em um obstáculo, que é a necessidade de um carregador florestal em cada unidade de extração florestal. Como são três os produtos extraídos das florestas: tora curta para serraria, tora longa para serraria e tora longa para torno, torna-se necessário o transporte simultâneo de todos os produtos, sendo os caminhões distribuídos uniformemente conforme mostra o modelo matemático, sendo, portanto, necessário a aquisição de mais um carregador florestal para viabilizar o modelo teórico.

- Devido ao fato de dois veículos da frota não possuírem assoalhos, estes não podem ser utilizados para o transporte de tora curta. Recomenda-se a realização de uma análise da viabilidade econômica para a colocação de assoalho nestes veículos, sendo que se esta modificação for realizada, os mesmos se tornarão adaptados ao transporte de tora curta, sendo assim mais uma opção para o transporte. As duas opções citadas acima (aquisição de mais um carregador florestal e colocação de assoalho nos veículos que não possuem), são as soluções mais viáveis economicamente para conseguir a maximização do volume de carga.

- Comparando-se o custo teórico obtido pelo método de programação linear ( $\mathrm{R} \$ 19.534,65)$, com o custo real médio mensal $(\mathrm{R} \$ 18.488,98)$, verifica-se uma pequena diferença, no valor de R\$ $1.045,67$ e o volume de madeira transportada é consideravelmente maior, partindo de 5.130 estéreos/mês (real) para 6.637,91 estéreos/mês (teórico), uma diferença de 1.507 estéreos, ou $22,70 \%$.

- O custo médio real por estéreo posto pátio é: $\mathrm{R} \$ 18.488,98 / 5.130$ (estéreos) $=\mathrm{R} \$$ 3,60/st. Através da programação linear, o custo teórico por estéreo posto pátio é: $\mathrm{R} \$ 19.534,65$ / 6.637 (estéreos) $=\mathrm{R} \$ 2,94$. Isto resulta em uma diminuição de $\mathrm{R} \$ 0,66$ por estéreo posto pátio ou $18,33 \%$, mostrando assim que o modelo traz resultados altamente significativos para os interesses da empresa. O ganho real que poderia ser obtido com o uso da programação linear chega a cifra de $\mathrm{R} \$$ $3.386,00$ reais mensais, o que poderia ser utilizado para a colocação de carrocerias nos caminhões, ou para aquisição ou aluguel de outro carregador florestal (longo prazo), o que reduziria ainda mais os custos de transporte da empresa, ou seja, o valor ganho com a colocação da carroceria nos caminhões que não a possuem e a aquisição de um carregador florestal, juntamente com o uso da programação linear traria um ganho muito mais expressivo em longo prazo para a empresa em estudo.

\section{REFERÊNCIAS}

AAB SCANIA. Vida Útil Econômica e Renovação de Frotas. São Paulo: 1985. 27 p.

ARCE, J. E. Um sistema de programação do transporte principal de multiprodutos florestais visando a minimização dos custos. Curitiba: 1997. Dissertação de Mestrado. Universidade Federal do Paraná - UFPR. 
BALLONI, E. A. Conjuntura florestal: situação atual e tendência dos reflorestamentos no Brasil. In $\mathbf{1}^{\circ}$ painel sobre ciência $\mathbf{e}$ conjuntura floresta na pós-graduação. 1997.

BRANDT, S. A. Análise dos sistemas de transporte de carvão vegetal. Viçosa: SIF, 1984, p. 77.

ISARD, Walter. Introduction to Regional Science. 1975. Lansing. Michigan States.

LEITE, A. M. P. Análise dos fatores que afetam o desempenho de veículos e o custo de transporte de madeira no distrito florestal do Vale do Rio Doce, MG. Viçosa MG: 1992. Dissertação de Mestrado. Universidade Federal de Viçosa - UFV.

MACHADO, C. C. Transporte Florestal Rodoviário. Viçosa: UFV. Impr. Univ. 1985. $38 \mathrm{p}$.

MALINOVSKI, J. R. \& FENNER, P. T. Otimização do transporte de madeira roliça de Pinus spp. Curitiba: FUPEF/UFPR. 1986, p. 68 .
MARQUES, R. T. Otimização de um sistema de transporte florestal rodoviário pelo método PERT / CPM. Viçosa: 1994. Dissertação de Mestrado. Universidade Federal de Viçosa - UFV.

MARTINI, E. L. \& BARBOSA L. N. Planejamento Florestal: A importância e da aplicação da programação linear. IN: ENCONTRO BRASILEIRO DE ECONOMIA FLORESTAL: 1. Proceedings. Curitiba: 1988. p. 545-74.

SAAB SCANIA. Scania desempenho. São Paulo: 1985. 27 p.

SALMERON, A. s.d. Exploração e abastecimento de madeira na Ripasa $\mathrm{S} / \mathrm{A}$ celulose e papel. Americana: Ripasa Florestal, p. 30. (1984).

SEIXAS, F. Uma metodologia de seleção e dimensionamento da frota de veículos rodoviários para o transporte principal de madeira. São Carlos: 1992. Tese de Doutorado. Universidade de São Paulo / USP.

SILVERSIDES, A. P. Um estudo de tempo e produção na exploração de povoamentos jovens de Douglas-fir com motoserra e "Skidder". Revista Árvore. 1978, p. 1-26. 